\title{
Spiritual Emotional Freedom Technique against Anxiety and Psychological Well-being of Type 2 DM Patients during the COVID-19 Pandemic
}

Ratna Yunita Sari ${ }^{1 *}$ (D) Abdul Muhith ${ }^{1}$, Riska Rohmawati ${ }^{1}$ D, Umdatus Soleha $^{1}$, Imamatul Faizah ${ }^{1}$, Raden Khairiyatul Afiyah $^{1}$ (D), Firman Suryadi Rahman ${ }^{2}$ (D)

${ }^{1}$ Lecturer of Master's Degree Program in Applied Nursing, Faculty of Nursing and Midwifery, Universitas Nahdlatul Ulama Surabaya, Surabaya, Indonesia; '²Doctoral Program of Public Health, Faculty of Public Health, Universitas Airlangga, Surabaya, Indonesia

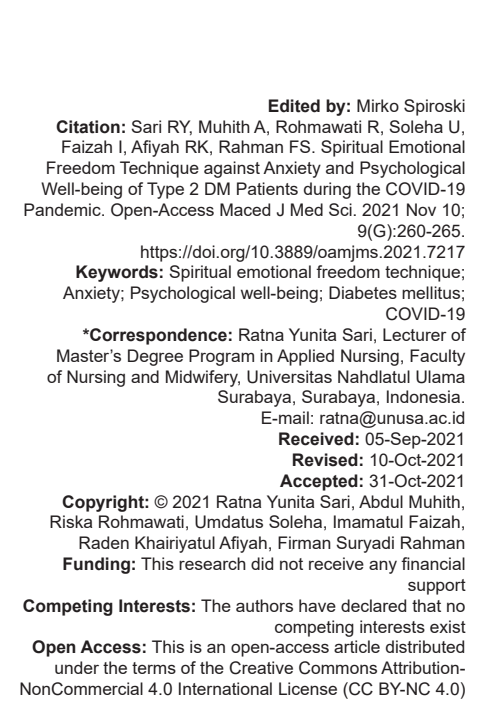

\begin{abstract}
BACKGROUND: The COVID-19 pandemic makes patients with type 2 diabetes mellitus experience an increase in anxiety, considering that diabetes mellitus is one of the dangerous comorbidities for people infected with the COVID-19 virus so that it affects their psychological well-being. Low psychological well-being will have an impact on decreasing self-care, thereby increasing the occurrence of complications.

AIM: The purpose of this study was to analyze the effect of the spiritual emotional freedom technique (SEFT) on anxiety and the psychological well-being of patients with type 2 DM during the COVID-19 pandemic.

METHODS: The research design employed is a quasi-experimental research with the untreated control group design with dependent pre-test and post-test samples. The sampling technique used is probability sampling which is a random sampling to meet the inclusion and exclusion criteria with a total sample of 110 respondents with the distribution of the intervention group consisting of 55 respondents and the control group consisting of 55 respondents. The instrument used to measure the level of anxiety is the Hamilton Rating Scale for Anxiety and psychological well-being of Ryff's psychological well-being. The statistical tests used are Paired Sample t-Test and Independent t-test with significant $p<0.05$

RESULTS: The results showed that the mean level of anxiety in the intervention group before the implementation of the intervention was 21.89 (moderate), while after the intervention was 10.98 (mild) and the psychological wellbeing before the intervention was 147.49 (low), while after the intervention was 170.91 (moderate). Furthermore, in the case of the control group, the mean level of anxiety before the intervention was 19.16 and after the intervention was 19.11 and psychological well-being before the intervention was 146.67 while after the intervention was 146.45 . Furthermore, the data analysis obtained that the SEFT affected the level of anxiety and psychological well-being of patients with type 2 diabetes during the COVID-19 pandemic with $p=0.00$
\end{abstract}

CONCLUSION: The SEFT that is routinely implemented can reduce the level of anxiety so that it can improve the psychological well-being of patients with type 2 DM during the COVID-19 pandemic.

\section{Introduction}

COVID-19 caused by the corona virus (SARS-CoV-2) has become a global pandemic affecting millions of lives and is one of the greatest health challenges on a global scale in this century [1]. No one can predict when the COVID-19 pandemic will end so that activities can return to normal or the pandemic situation will continue in the future [2]. This condition can trigger individuals to experience stress and people tend to fear falling sick, feeling helpless, and stigmatizing [3]. Comorbidities such as diabetes mellitus are one of the dangerous comorbid factors that double the risk of increasing complications and death for people infected with COVID-19 [4]. The patients with type 2 diabetes mellitus also have many psychosocial problems, which coupled with the anxiety and psychological stress of a pandemic, physical distancing, lockdown, and quarantine which creates an unpleasant situation [5], [6], [7]. Patients with type 2 diabetes mellitus who experience mental problems with complex situations can cause difficulties in psychologically adapting to the current situation [1]. Feelings of high anxiety that cannot be controlled or controlled refer to negative emotions such as feeling hopeless, angry or frustrated which will affect psychological well-being in people with type 2 diabetes mellitus [1], [8], [9]. The low psychological well-being of patients with type 2 diabetes mellitus results in low self-care so that it will increase the occurrence of complications [10].

Data in Indonesia recorded the number of positive cases of COVID-19 on January 21, 2021 of around 1,012,350 infected people and on May 22, 2021, it increased sharply to $1,769,940$ cases [11]. Meanwhile, 
in Surabaya City, the number of positive cases on July 22, 2020, out of 7994 confirmed cases of COVID-19, recorded 251 deaths accompanied by diabetes mellitus [12]. Research from Alessi discovered that $43 \%$ of people with type 2 DM experienced psychological stress during the COVID-19 pandemic [8]. In addition 7200 people in China during the lockdown imposed in February 2020, one-third of respondents experienced general anxiety disorder related to COVID-19, while about one-fifth felt signs of depression [12]

Psychological pressure caused by anxiety will also affect the psychological well-being of DM sufferers during the COVID-19 pandemic. Decreased psychological well-being if allowed to drag on for a long time will have an impact on physical and psychological health [13], [14], [15]. If physical and psychological health conditions are in poor condition, it can cause feelings of sadness, loss of motivation for the future, and decreased self-confidence [6]. Management that can be used in the treatment to improve psychological problems with type 2 diabetes mellitus patients with non-pharmacological interventions, one of which is the Spiritual Emotional Freedom Technique (SEFT) [16]. SEFT is a therapeutic technique that uses the energy that is within him to take advantage of energy points with a certain number of strengths and sequences added with spiritual elements that will have a relaxing effect and cause sincerity, positive acceptance, and hope of healing which will later affect the decrease in feelings of anxiety experienced and improve a person's psychological well-being so that their health status can be well maintained during the current COVID-19 pandemic situation. According to Massey, Feig, and Duque-Serrano in their research, they stated that awareness-based Well-being interventions can improve self-care, empathy, quality of life, and can reduce stress in patients with type 2 diabetes mellitus [10], [17], [18], [19].

According to Cruch et al. [20], based on the results of their research, it was revealed that the Emotional Freedom Technique which were given to the respondents were very effective in reducing stress levels, indicated by a decrease in cortisol levels. The awareness-based psychological well-being interventions can improve self-care, empathy, quality of life and can reduce DM-related stress [10]. Patients who have spiritual health will be connected to the highest power, have meaning and purpose in life, and can have a better defense with their illness. The addition of spiritual elements in the intervention will also add an amplifying effect that will lead to a sense of sincerity, positive acceptance of the illness being suffered through fortitude, hope for recovery, and being able to take lessons [20]. Therefore, the purpose of this study was to determine the effect of the SEFT on anxiety and psychological well-being of Type 2 DM Patients during the COVID-19 Pandemic.

\section{Method}

\section{General background of research}

This study employed quasi-experimental research with untreated control group design approach and dependent pre- and post-test samples.

\section{Sample of research}

The population involved in this study was all patients with type 2 DM who were recorded at the Elderly Integrated Health Service Center of Sapta Lestri RW 007 of Sidotopo Sub-District Wetan Surabaya. Sampling was carried out purposively under the inclusion criteria of type 2 diabetes mellitus patients with controlled sugar levels in the past 3 months, aged 20-69 years, able to communicate well, and willing to follow the entire training program to the end. Meanwhile, the exclusion criteria are patients experiencing neurological complications, retinopathy, and severe psychological disorders. Based on the criteria, the total respondents in this study were 110 respondents with the distribution of 55 respondents in the intervention group and 55 respondents in the control group.

\section{Instrument and procedures}

The instrument used to measure the level of anxiety is the Hamilton Rating Scale for Anxiety (HARS) questionnaire (Thompson, 2015) while the instrument used to measure the psychological well-being was the Ryff's psychological well-being questionnaire (Ryff, 1989). The results of the validity and reliability test of the Hamilton Rating Scale for Anxiety (HARS) questionnaire were not carried out because they have been standardized by international standards and have been published. Meanwhile, Ryff's psychological well-being questionnaire validity was tested with a sample of 124 people and obtained correlation value of each question within a range of $0.306-0.731$ and Cronbach alpha reliability of 0.845 (Amalia, 2016). Therefore, these results considered that the Hamilton Rating Scale for Anxiety (HARS) questionnaire and Ryff's psychological well-being questionnaire are valid and reliable to be used in this research. This research was conducted in May-June 2021. The pre-test was carried out one day before the intervention was carried out. The researchers acted as therapists who were assisted by research assistants where the intervention group received SEFT carried out every day for 2 weeks for \pm 30 min during the training process with 3 stages starting from Set-Up, Tune-In, and Tapping. The control group was not given any intervention, only to carry out the routines (habits) of each respondent. The post-test was carried out 1 day after the intervention. This research has been approved by the Ethics Committee 
of the Brahmanda Lentera Chakra Institute with the number 023/07/IV/EC/KEPK/Lamb.Candle/2021.

To minimize bias, there were sample inclusion criteria:

1. Do not exercise during the intervention

2. Daily activities and nutritional patterns according to daily habits

3. Blood sugar levels are controlled and within normal limits in the past 3 months.

\section{Selection of research location:}

The location has a large elderly population and during the COVID-19 pandemic did not receive education about improving health and health services so that it increased anxiety because the elderly were a high risk group for exposure to COVID-19.

\section{Data analysis}

The normality of the data was tested using Kolmogorov-Smirnov, and the data were normally distributed so that it was continued with data analysis using the Paired t-test for data before and after on the level of anxiety and psychological well-being. The post-test data of the intervention group and the control group were analyzed using the Independent t-test with a hypothesis of $p<0.05$.

\section{Results}

The characteristics of the participants in this study were based on age, gender, education, occupation, duration of suffering from diabetes mellitus, and comorbidities. The results of the characteristics of respondents in the study are as follows:

Table 1 shows that the characteristics of the research respondents obtained results that almost half $(32.7 \%)$ were in late old age (56-65 years) in the intervention group and almost half (34.5\%) were in early old age (46-55) in the control group. In terms of the gender in the intervention group and the control group, almost half of them were female $(54.5 \%$ and $63.6 \%$ ). Based on the educational background in the intervention group, almost half $(50.9 \%)$ and most of the respondents in the control group $(63.6 \%)$ were in the secondary education category with employment status in the intervention group are mostly (54.5\%) and almost half of the control group (49.1\%) work as selfemployed. Based on the characteristics of the duration of suffering from diabetes mellitus, it was found that in the intervention group and the control group, almost half $(45.5 \%$ and $41.8 \%)$ had diabetes mellitus for 1-3 years. For comorbidities in both the intervention and control groups, most $(74.5 \%$ and $60 \%)$ did not have
Table 1: Characteristics of respondents in the intervention group and control group

\begin{tabular}{|c|c|c|c|c|}
\hline \multirow[t]{2}{*}{ Characteristics } & \multicolumn{2}{|c|}{ Intervention group $(\mathrm{n}=55)$} & \multicolumn{2}{|c|}{ Control group $(n=55)$} \\
\hline & $\bar{f}$ & $\%$ & $f$ & $\%$ \\
\hline \multicolumn{5}{|l|}{ Age (years) } \\
\hline Early adulthood (26-35) & 8 & 16.4 & 8 & 14.5 \\
\hline Late adulthood (36-45) & 14 & 25.5 & 17 & 30.9 \\
\hline Early old age (46-55) & 14 & 25.5 & 19 & 34.5 \\
\hline Late old age (56-65) & 18 & 32.7 & 11 & 20.0 \\
\hline \multicolumn{5}{|l|}{ Gender } \\
\hline Male & 25 & 45.5 & 20 & 36.4 \\
\hline Female & 30 & 54.5 & 35 & 63.6 \\
\hline \multicolumn{5}{|l|}{ Education } \\
\hline Basic & 20 & 36.4 & 20 & 36.4 \\
\hline Intermediate & 28 & 50.9 & 30 & 63.6 \\
\hline High & 7 & 12.7 & 5 & 9.1 \\
\hline \multicolumn{5}{|l|}{ Profession } \\
\hline Civil servants & 7 & 12.7 & 4 & 7.3 \\
\hline Entrepreneur & 30 & 54.5 & 27 & 49.1 \\
\hline House wife & 17 & 30.9 & 20 & 36.4 \\
\hline Unemployed & 1 & 1.8 & 4 & 7.3 \\
\hline \multicolumn{5}{|l|}{ Length of suffering from DM } \\
\hline $1-3$ years & 25 & 45.5 & 22 & 40.0 \\
\hline $4-5$ years & 23 & 41.8 & 23 & 41.8 \\
\hline$>5$ years & 7 & 12.7 & 10 & 18.2 \\
\hline \multicolumn{5}{|l|}{ Comorbidities } \\
\hline Yes & 14 & 25.5 & 22 & 40.0 \\
\hline Not & 41 & 74.5 & 33 & 60.0 \\
\hline
\end{tabular}

comorbidities.

Table 2 shows that the average value of the anxiety level in the intervention group before the action was 21.89 (high anxiety level) and after the action, the average anxiety level was 10.98 (mild anxiety level). For psychological well-being in the intervention group, before the action was taken, an average of 147.49 (low) was obtained and after the intervention, the average value was 170.91 (medium) with $p=0.000$ which means that there was a decrease in anxiety levels and a significant increase in psychological well-being before and after given the SEFT intervention. Meanwhile, in the control group, the average anxiety level before the action was 19.16 (moderate) and 19.11 (moderate) after the action with a $p=0.568$. For psychological well-being before the action, the average value was 146.67 (low), and after the action was 146.45 (low) with $p=0.699$, which means there was no decrease in anxiety level or increase in psychological well-being in the control group.

Table 3 shows that from the results of data analysis, the $p=0.000$ was obtained on the level of anxiety and psychological well-being, which means that there were differences in levels of anxiety and psychological well-being before and after the SEFT intervention.

\section{Discussion}

Psychological disorders are closely related to people with type 2 diabetes mellitus as a result of the many treatments that must be done. In addition, the current COVID-19 pandemic situation has greatly impacted the mental health of patients with type 2 diabetes mellitus. The results of systematic reviews 
Table 2: Levels of anxiety and psychological well-being in pre and post in the intervention and control group

\begin{tabular}{|c|c|c|c|c|c|c|c|c|c|}
\hline \multirow[t]{2}{*}{ Variable } & \multirow[t]{2}{*}{ Group } & \multicolumn{2}{|l|}{ Pre } & \multicolumn{2}{|l|}{ Post } & \multirow[t]{2}{*}{$95 \% \mathrm{Cl}$} & \multirow[t]{2}{*}{$t$} & \multirow[t]{2}{*}{$\mathrm{n}$} & \multirow[t]{2}{*}{$p$-value } \\
\hline & & Mean & SD & Mean & SD & & & & \\
\hline \multirow[t]{2}{*}{ Anxiety } & Intervention & 21.89 & 12.18 & 10.98 & 6.54 & $(8.46)-(13.35)$ & 8.94 & 55 & 0.000 \\
\hline & Control & 19.16 & 11.15 & 19.11 & 11.13 & $(-0.136)-(-0.245)$ & 0.57 & 55 & 0.568 \\
\hline \multirow[t]{2}{*}{ Psychological well-being } & Intervention & 147.49 & 27.19 & 170.91 & 38.73 & $(-29.94)-(-16.88)$ & -7.91 & 55 & 0.000 \\
\hline & Control & 146.67 & 26.00 & 146.45 & 27.72 & $(-0.906)-(1.342)$ & 0.38 & 55 & 0.699 \\
\hline
\end{tabular}

of studies showed that people who have chronic diseases such as diabetes mellitus are more affected by COVID-19 compared to healthy people, where the risk of contracting Sars-CoV-2 is higher which will worsen health conditions and increase the risk of death [3], [21]. These conditions trigger symptoms of psychological disorders such as anxiety, stress, and depression which tend to appear higher in individuals with comorbidities [22]. This is in line with the results of the study where patients with type 2 diabetes mellitus in the intervention group experienced an average level of anxiety in the high category while the control group experienced an average level of anxiety in the moderate category before the intervention was implemented. From the interview results, the most of the respondents stated that the anxiety experienced was mainly due to fear of contracting the coronavirus infection due to the age factor that was exposed to it plus comorbid factors. Furthermore, the uncertain condition of the COVID-19 pandemic situation, government policies in overcoming the COVID-19 pandemic often change so that it has an impact on socio-economic conditions. In addition, there are still many people who do not comply with health protocols, thus increasing cases of transmission and news of patient deaths that mostly occur in people with a history of comorbidities such as type 2 diabetes mellitus. This is supported by the results of research carried out by Al -Sofiani et al. [23] which showed that the prevalence of symptoms of depression and anxiety in people with diabetes was $62 \%$ and $44 \%$, which arise due to fear of contracting the coronavirus infection, running out of diabetes medication, and requiring hospitalization due to hypoglycemia or hyperglycemia [23].

The health condition of people with type 2 diabetes mellitus due to their illness and feelings of anxiety due to the COVID-19 pandemic situation will affect their psychological well-being [24]. This is in accordance with the results of the study which showed that the average psychological well-being in the intervention and control groups was in a low category. This is supported by a statement from Dave [25] where poor psychological well-being is more common in patients with type 2 diabetes mellitus than in other diseases. Moreover, this is coupled with the COVID-19 pandemic condition which has indeed made patients with type 2 diabetes mellitus have poor psychosocial health [26]. Anxiety conditions and low psychological well-being if not addressed will result in feelings of sadness, loss of motivation for the future, and decreased self-confidence [6]. Management that can be used in the treatment to improve psychological problems with type 2 diabetes mellitus patients with non-pharmacological interventions, one of which is the SEFT [16].

The results of the research conducted showed that there was a significant influence of SEFT on the level of anxiety and psychological well-being of people with type 2 diabetes mellitus during the COVID-19 pandemic. Based on the mean results, the intervention group showed a decrease in anxiety levels and an increase in psychological well-being after being given the SEFT. The results of this study are in line with research conducted by Dincer and Inangil (2021) which showed that Emotional Freedom Techniques (EFT) can reduce anxiety levels [27]. In addition, another study from Messey showed that awareness-based psychological well-being interventions can improve self-care, empathy, quality of life and can reduce DM-related stress [10].

The SEFT has the same basic principles as the EFT. However, in SEFT there is a spiritual subject (prayer) at the set-up stage of the therapy section. Prayer in therapy is beneficial for "Psychological Reversal" which affects psychological health which creates hope, fortitude, and wisdom as well as social aspects so that it can neutralize emotions and minimize anxiety to increase the psychological well-being that exists within him [28]. Neutralization of negative emotions and physical pain is in the tune-in phase, where prayer is performed simultaneously with tapping. Tapping that is done can stimulate "electrically active cells" as an active center consisting of active cells on the surface of the body that will cause the delivery of stimuli in the form of signal transduction that occurs in biological processes due to stimuli carried out at the main point. The next signal transduction will stimulate the pituitary gland to release endorphins hormones so that individuals feel calm, relaxed, and comfortable [29]. In addition, tapping that is done will produce signals that are sent directly to the amygdala and other brain structures in the limbic

Table 3: The value of the difference in levels of anxiety and psychological well-being pre and post in the intervention group and the control group

\begin{tabular}{|c|c|c|c|c|c|c|c|c|c|c|}
\hline \multirow[t]{2}{*}{$\begin{array}{l}\text { Variable } \\
\text { nat }\end{array}$} & \multirow[t]{2}{*}{ Group } & \multirow[t]{2}{*}{ Mean } & \multirow[t]{2}{*}{ SD } & \multirow[t]{2}{*}{ SE } & \multirow[t]{2}{*}{$\mathrm{n}$} & \multirow[t]{2}{*}{ Mean Difference } & \multirow[t]{2}{*}{$\mathrm{t}$} & \multirow[t]{2}{*}{$95 \% \mathrm{Cl}$} & \multicolumn{2}{|c|}{$\mathrm{p}$-value } \\
\hline & & & & & & & & & Pre & Post \\
\hline Anxiety & $\begin{array}{l}\text { Intervention } \\
\text { Control }\end{array}$ & $\begin{array}{l}10.98 \\
19.11\end{array}$ & $\begin{array}{l}6.54 \\
11.13\end{array}$ & $\begin{array}{l}0.88 \\
1.50\end{array}$ & $\begin{array}{l}55 \\
55\end{array}$ & -8.127 & -4.66 & $(-11.57)-(-4.67)$ & 0.223 & 0.000 \\
\hline Psychological well-being & $\begin{array}{l}\text { Intervention } \\
\text { Control }\end{array}$ & $\begin{array}{l}170.91 \\
146.45\end{array}$ & $\begin{array}{l}38.73 \\
27.72\end{array}$ & $\begin{array}{l}5.22 \\
3.73\end{array}$ & $\begin{array}{l}55 \\
55\end{array}$ & 24.45 & 3.80 & $(11.72)-(37.18)$ & 0.872 & 0.000 \\
\hline
\end{tabular}


that process fear, the impact of which can reduce the frequency of brain waves associated with stress [19].

SEFT apart from having an element of prayer also focuses on belief, sincerity, submission, and gratitude, which also helps in reducing anxiety levels. This is supported by the statement that most of the respondents after doing the SEFT, stated that it was during the prayer stage while patting that a feeling of relaxation, comfort, and calm appeared so that the feeling of anxiety was reduced accompanied by a feeling of getting closer to God, the emergence of a sense of sincerity, surrender, be grateful for all the conditions that are being faced and bring up a new spirit to maintain their health. A research support that reading and listening to the Qur'an, dhikr, and prayer are more effective than relaxation in creating peace of mind because worship is most under human nature so that it emerges peace of mind, feeling of relaxation, and feelings of happiness [30]. In addition research also showed that the SEFT can reduce anxiety levels, generate hope, and increase happiness so that it can heal physical and psychological health.

The success of SEFT in reducing anxiety levels and increasing psychological well-being cannot be separated from the educational background of the respondents. From the results of the study, it was found that almost half of the intervention group and the control group had a secondary education background and stated that a person's high educational background will form an adaptive pattern of feelings of anxiety because they have a better coping pattern (Kaplan and Sadock, 2015). In addition, the higher the level of education a person has, the faster and more responsive they are in receiving information so that feeling of anxiety related to the conditions suffered can be well received and will be more open to accepting their conditions, creating new hope and autonomy that can improve psychological well-being [6], [16], [17], [18], [19], [20], [21], [22], [23], [24], [25], [26], [27], [28], [29], [30], [31].

The limitation of this research is the inability to collect the elderly in one place to be given education so that education is given door to door. Implications: Nurses act as educators by providing SEFT interventions to overcome anxiety problems in the elderly during the COVID-19 Pandemic

\section{Suggestions for further researchers:}

1. Doing research by checking cortisol results

2. Adding the population

3. Expanding the research area.

\section{Conclusion}

SEFT that was carried out regularly can reduce anxiety levels and increase Psychological well-being in patients with type 2 diabetes mellitus amid the COVID-19 pandemic. A decrease in anxiety levels and an increase in psychological well-being in patients with type 2 diabetes mellitus will have an impact in improving health status both physically and psychologically during the COVID-19 pandemic. Therefore, it is important to innovate in the provision of health services such as establishing a multidisciplinary clinic or collaborating with first-level health services to address diabetes management to include psychological management to provide comprehensive health services that provide physical and mental health care for people with type 2 diabetes mellitus during the COVID-19 pandemic.

\section{Acknowledgments}

The author would like to thank each of our team members for their hard work and dedication. We would also like to thank the Head of Integrated Health Service Center of Sapta Lestari and Integrated Health Service Center cadres, respondents, and parties assisting the research process.

\section{References}

1. Singhai K, Swami MK, Nebhinani N, Rastogi A, Jude E. Psychological adaptive difficulties and their management during COVID-19 pandemic in people with diabetes mellitus. Diabetes Metab Syndr. 2020;14(6):1603-5. https://doi.org/10.1016/j. dsx.2020.08.025

PMid:32862099

2. Hall G, Laddu DR, Phillips SA, Lavie CJ, Arena R. A tale of two pandemics: How will COVID-19 and global trends in physical inactivity and sedentary behavior affect one another? Prog Cardiovasc Dis. 2021;64:108-10. https://doi.org/10.1016/j. pcad.2020.04.005

PMid:32277997

3. Wang C, Pan R, Wan X, Tan Y, Xu L, Ho CS, Ho RC. Immediate psychological responses and associated factors during the initial stage of the 2019 Coronavirus disease (COVID-19) epidemic among the general population in China. Int J Environ Res Public Health. 2020;17(5):1729.

PMid:32155789

4. Muniyappa R, Gubbi S. COVID-19 pandemic, coronaviruses, and diabetes mellitus. Am J Physiol Endocrinol Metab. 2020;318(5):E736-41. https://doi.org/10.1152/ ajpendo.00124.2020 PMid:32228322

5. Dubey MJ, Ghosh R, Chatterjee S, Biswas P, Chatterjee S, Dubey S. COVID-19 and addiction. Diabetes Metab Syndr. 2020;14(5):817-23. https://doi.org/10.1016/j.dsx.2020.06.008 PMid:32540735

6. Kalra S, Jena BN, Yeravdekar R. Emotional and psychologica needs of people with diabetes. Indian $\mathrm{J}$ Endocrinol Metab. 2018;22(5):696-704. https://doi.org/10.4103/ijem.IJEM_579_17 
PMid:30294583

7. Majumdar P, Biswas A, Sahu S. COVID-19 pandemic and lockdown: Cause of sleep disruption, depression, somatic pain, and increased screen exposure of office workers and students of India. Chronobiol Int. 2020;37(8):1191-200. https://doi.org/10 .1080/07420528.2020.1786107

PMid:32660352

8. Alessi J, De Oliveira GB, Franco DW, Do Amaral BB, Becker AS, Knijnik CP, et al. Mental health in the era of COVID-19: Prevalence of psychiatric disorders in a cohort of patients with Type 1 and Type 2 diabetes during the social distancing. Diabetol Metab Syndr. 2020;12:76. https://doi.org/10.1186/ s13098-020-00584-6 PMid:32879637

9. Arifin H, Kusnanto K, Widyawati IY. How did I feel before becoming diabetes resilience? A qualitative study in adult Type 2 diabetes mellitus. Indones Nurs J Educ Clin. 2020;5(1):27-34.

10. Massey CN, Feig EH, Duque-Serrano L, Huffman JC. Psychological well-being and Type 2 diabetes. Curr Res Diabetes Obes J. 2017:4(4):555641. https://doi.org/10.19080/ crdoj.2017.04.555641

PMid:29276801

11. Ministry of Health Indonesia. COVID-19 Data for New Cases. Jakarta: Ministry of Health Indonesia; 2019.

12. Gao W, Ping S, Liu X. Gender differences in depression, anxiety, and stress among college students: A longitudinal study from China. J Affect Disord. 2020;263:292-300. https://doi. org/10.1016/j.jad.2019.11.121

PMid:31818792

13. Chew BH, Shariff-Ghazali S, Fernandez A. Psychological aspects of diabetes care: Effecting behavioral change in patients. World J Diabetes. 2014;5(6):796-808. https://doi. org/10.4239/wjd.v5.i6.796

PMid:25512782

14. Ng KY, Zhou S, Tan SH, Ishak ND, Goh ZZ, Chua ZY, et al. Understanding the psychological impact of COVID-19 pandemic on patients with cancer, their caregivers, and health care workers in Singapore. JCO Glob Oncol. 2020;6:1494-509. https://doi.org/10.1200/GO.20.00374 PMid:33017179

15. Zhong B, Huang Y, Liu Q. Mental health toll from the Coronavirus: Social media usage reveals Wuhan residents' depression and secondary trauma in the COVID-19 outbreak. Comput Human Behav. 2021;114:106524. https://doi.org/10.1016/j. chb.2020.106524

PMid:32836728

16. Ma'rifah AR, Handayani RN, Dewi P. The effectiveness of fingerhold relaxation technique and spiritual emosional freedom technique (SEFT) to the pain intensity scale on patients with post caesarean section. J Matern Care Reprod Health. 2018;1(2):325-40.

17. Bach D, Groesbeck G, Stapleton P, Sims R, Blickheuser K, Church D. Clinical EFT (emotional freedom techniques) improves multiple physiological markers of health. J Evid Based Integr Med. 2019;24:1-12. https://doi.org/10.1177/2515690X18823691 PMid:30777453

18. Banerjee P, Puri A, Luqman N. Emotional freedom technique: An alternative therapy in destressing. Int J Appl Innov Eng Manag. 2015;4(9):19-26.
19. Church D, Yount G, Brooks AJ. The effect of emotional freedom techniques on stress biochemistry: A randomized controlled trial. J Nerv Ment Dis. 2012;200(10):891-6.

PMid:22986277

20. Fisher J, Brumley D. Nurses' and carers' spiritual wellbeing in the workplace. Aust J Adv Nurs. 2008;25(4):49-57.

21. Liu $\mathrm{H}$, Chen $\mathrm{S}$, Liu M, Nie H, Lu H. Comorbid chronic diseases are strongly correlated with disease severity among COVID-19 patients: A systematic review and meta-analysis. Aging Dis. 2020;11(3):668-78. https://doi.org/10.14336/AD.2020.0502 PMid:32489711

22. Ozamiz-Etxebarria N, Dosil-Santamaria M Picaza-Gorrochategui M, Idoiaga-Mondragon N. Stress, anxiety, and depression levels in the initial stage of the COVID-19 outbreak in a population sample in the Northern Spain. Cad Saude Publica. 2020;36(4):e00054020. https://doi. org/10.1590/0102-311X00054020 PMid:32374806

23. Al-Sofiani ME, Albunyan S, Alguwaihes AM, Kalyani RR, Golden SH, Alfadda A. Determinants of mental health outcomes among people with and without diabetes during the COVID-19 outbreak in the Arab Gulf region. J Diabetes. 2021;13(4):339-352. https://doi.org/10.1111/1753-0407.13149 PMid:33351239

24. Carriedo A, Cecchini JA, Fernandez-Rio J, Méndez-Giménez A COVID-19, psychological well-being and physical activity levels in older adults during the nationwide lockdown in Spain. Am J Geriatr Psychiatry. 2020;28(11):1146-55. https://doi. org/10.1016/j.jagp.2020.08.007

PMid:32919872

25. Davies M. Psychological aspects of diabetes management Medicine. 2019;47(2):131-4.

26. Joensen LE, Madsen KP, Holm L, Nielsen KA, Rod MH, Petersen AA, et al. Diabetes and COVID-19: Psychosocial consequences of the COVID-19 pandemic in people with diabetes in Denmark-what characterizes people with high levels of COVID-19-related worries? Diabet Med. 2020;37(7):1146-54. https://doi.org/10.1111/dme.14319 PMid:32392380

27. Dincer $B$, Inangil $D$. The effect of emotional freedom techniques on nurses' stress, anxiety, and burnout levels during the COVID-19 pandemic: A randomized controlled trial. Explore (NY). 2021;17(2):109-14. https://doi.org/10.1016/j.explore PMid:33293201

28. Waite WL, Holder MD. Assessment of the emotional freedom technique: An alternative treatment for fear. Sci Rev Ment Health Pract. 2003;2(1):20-6.

29. Pluskal T, Weng JK. Natural product modulators of human sensations and mood: Molecular mechanisms and therapeutic potential. Chem Soc Rev. 2018;47(5):1592-637. https://doi. org/10.1039/c7cs00411g PMid:28933478

30. Elvina M. Integrative medicine through islamic perspective in respecting pandemic COVID-19. Int J Islamic Med. 2020;1(1):43-52.

31. Khodai A, Bagheri M, Kh F. The relationship between mindfulness, self-differentiation and borderline personality traits with the mediation role of Alexithymia. J Psychol Achiev. 2020;27(2):49-68. 